\title{
LA POESÍA DE PERO MEOGO Tenue hilo narrativo y lírica efusión
}

\author{
por \\ JAIME FERREIRO ALEMPARTE
}

\begin{abstract}
Las cantigas de amigo son, por su contenido sentimental, brevedad y disposición formal, composiciones eminentemente líricas. Nos seducen con fuerza irresistible, y esta seducción es tanto más grande cuanto mayor es su resistencia a entregarnos el último secreto, sugerido, pero nunca del todo desvelado. Entrega y resistencia es cualidad inmanente y peculiar de toda manifestación lírica, que hunde sus raíces en el Eros universal. La dificultad de fijar y retener algo seguro en la alada materia que informa esta composiciones se incrementa en relación con la lejanía que las separa de nosotros. Pero semejante dificultad constituye también su mayor incentivo. Ello explica que la literatura sobre los cancioneros líricos galaico-portugueses sea ya muy extensa. Y dentro de este contexto, la obra lírica de Pero Meogo ha merecido expecial atención de todos los investigadores que han tratado de la lírica medieval. Tenemos además dos libros dedicados ex profeso a estudiar su poesía: $O$ Cancioneiro de Pero Meogo, de X.L. Méndez Ferrín (Vigo, 1966); y el de Leodegário A. De Azevedo Filho, As Cantigas de Pero Meogo (Brasilea, 1981). Son dos libros indispensables para el conocimiento de la obra de uno de los poetas más señeros, si no es el más, de todos los que integran el "corpus" lírico del Cancionero medieval tal como hoy lo conocemos.

La mayoría de los críticos parecen estar de acuerdo en ver estas cantigas como un conjunto narrativo tejido en torno a "una historia de amor",
\end{abstract}


según frase acuñada por Filgueira Valverde. A. de Azevedo, el estudioso más reciente de las cantigas de Pero Meogo, escribe: "No conjunto... há uma forma lírica que se investe de sentido narrativo. De inicio observa-se que as personagens e os símbolos poéticos são os mesmos, da primeira à última composição. Em seguida os segmentos narrativos das cantigas anteriores são retomados e acrescidos de nova carga informativa, estabelencendo-se assim uma sequiéncia de ações". Declara sin embargo que se trata de "uma forma lírica" investida de sentido narrativo. Presumo que con la expresión "forma lírica" está pensando en la estructura formal que adopta la cantiga, pues la esencialidad de lo lírico, como sabemos por la Poéticade Staiger, no radica en la forma, que no es más que la cobertura que la hace, por así decirlo, tangible, viable, sino en un estado anímico concorde (Stimmung), inefablemente emotivo que nos invade y colma. Ese estado anímico, a pesar de su inestabilidad y fugitiva presencia, capaz no obstante de reproducir y suscitar en cada sujeto receptor una emoción similar, ha quedado prendido y eternizado en la canción, das Lied. El estado del alma se configura de acuerdo con su naturaleza. La canción, por la brevedad, la iteración y la disposición paratáctica, es la "forma" más idónea para captar y condensar ese fluido elemento que es lo lírico. No sería, pues, la forma lírica la que se reviste de sentido narrativo, sino al contrario, la forma narrativa la que se reviste de sentido lírico por obra mágica del poeta, que da a su criatura interior la forma precisa para su consitencia y pervivencia.

Con esta consideración creemos estar más cerca de Méndez Ferrín, que no cree en la unidad narrativa de las composiciones de Pero Meogo, pero sí en su "unidad estilística", la cual, claro está, no puede estar determinada por la mera estructura formal, sino por el efluvio lírico que las alienta y plenifica. Azevedo, en la misma página del pasaje reproducido y comentado, añade: "Em sintese, a forma narrativa esiste porque apresenta os quatro elementos que lhe sao própios: personagens, açãs, tempo e espaço". Ahora ha invertido los términos y dice más acertadamente "forma narrativa". De acuerdo. Pero tales características son consustanciales a toda la poesía medieval. Todavía estaba muy lejos de la mente de la época decir, desligada de esos elementos enumeroados por Azevedo. En al poética medieval no se da de hecho una lírica independiente de estados anímicos en sentido estricto, como ocurre en la lírica moderna; lo que sí se dan son manifestaciones líricas encarnadas en personajes y acciones en el espacio y en el tiempo. Lo decisivo aquí no es la trama narrativa, más bien sugerida que expresada. La trama se sobreentiende, pero no es indispensable para el goce lírico. Su acentuación resultaría más bien perturbadora. Lo que nos conmueve y deleita en las cantigas de Pero Meogo no es la trama, siempre tenuemente entrevista, evanescente y sutil, sino la atmós- 
fera que las impregna y baña, borrando sus aristas y sumergiéndonos en un mundo en cierto modo paradisíaco. También los símbolos están concebidos tan sólo como vehículos destinados a la recpeción y motivación de lo lírico. Tras esta determinación prioritaria de los lírico, vamos ahora, por vía más vivencial que conceptual cada una de las cantigas de Pero Meogo. Tal vez un sentimiento compartido nos permita descubrir alusiones histórico-culturales apenas reconstruibles para nosotros por procedimientos meramente terminológicos o semióticos.

\section{Cantiga I}

He aquí la tenue trama argumental: La amante (amiga) concierta con el amado (amigo) un encuentro en la fuente donde los ciervos van a beber, y teme que el amigo se enfuerezca si, a causa del miedo de la madre por la virginal integridad de la hija, no acude a la cita. La hija se dirige, pues, a la madre, que sin duda la escucha en escéptica actitud, en estos términos:

1 O meu amig'a que preyto talhei, con vosso medo, madre, mentirlh'ey.

E se non for, assanhars'á.

4 Talheilh éu preyto de o hir veer ena fonte hu os cervos van bever.

E se non for, assanhars'á.

7 Enon ey eu de lhi mentir sabor, mays mentirlh éy con vosso pavor.

E se non for, assahars'á.

10 De lhi mentir nen hun sabor non ey, con vosso med'a mentir lhaverey.

E se non for, assahars'á.

La puntuación de un texto medieval, y sobre todo de una cantiga, que es la encarnación más pura de lo lírico, reviste singular importancia, pero entraña a la vez esencial dificultad, no sólo porque los manuscritos no suelen indicarla, sino también por la índole misma del texto lírico, no sometible al criterio por el que se rige un texto no lírico. La lejanía que lo separa de nosotros hace todavía más problemática su precisión. A pesar de todas estas salvedades es evidente que aquí el criterio a seguir no es tanto de naturaleza gramatical, sino más bien musical; no depende de razones lógicas, sino, valga decirlo en sentido de Pascal, de causas cuya "ultima ratio" reside en los dominios del sentimiento. El uso o no de la coma rebasa en esta esfera el criterio exclusivamente ortográfico. Una pausa melódica, un matiz de entonación, un subrayado, son aspectos de mayor relevancia que una mera consideración de tipo sintáctico. En los caos en que lo gramatical y lo musical coinciden, la decisión no es dudo- 
sa. Pero debe renunciarse al empleo de la coma cuando ésta perturbe la secuencia de la onda lírica, trasunto de la fluencia anímica. La primera cantiga de Pero Meogo nos da ya pie para justificar nuestro punto de vista, al que pretendemos mantenernos fieles a lo largo de esta exposición sin volver expresamente sobre ello.

Méndez Ferrín y A. de Azevedo, los dos autores que han intentado establecer más cuidadosa y circunstanciadamente la puntuación, nos ofrecen un ejemplo bien ilustrativo sobre el problema objeto de esta consideración. Así M. Ferrín no pone coma después de la $o$ elidida de amigo en el primer verso, porque piensa "que non se pode pór vírgula entre das vocás elididas por ser a vírgula siño ortográfico de pausa, e se ésta se producira, rompería a elisión faguendo reaparecer os dous fonemas neutralizados". Aunque la coma sea un signo ortográfico de pausa, no es absulutamente necesario que lo sea en un texto lírico. Y por esto mismo tampoco creemos que la coma rompa la elisión como no rompería la sinalefa, que es aquí a la que métricamente se acerca, y por lo tanto, sin que nos dé la impresión de una apócope de la $o$. Azevedo, en cambio, pone coma, porque entiende "que o criterio sintático de puntuação não altera a realidade fonética do enunciado, permanecendo clara a elisão em: $a m i g^{\prime}, a^{\prime \prime}$. La coma no altera ciertamente en este caso la realidad fonética del enunciado; al contrrario, sirve para delimitar un leve inciso hecho de paso, que insinúa sobre la marcha, mediante un ligero cambio de entonación, una promesa hecha al amigo, promesa que percibimos en el estribillo, pero que no se declara del todo hasta el primer verso del segundo dístico: "... de o hir veer". La coma aquí no depende, pues, de un criterio estrictamente sintáctico u ortográfico, sino de un período intencionalmente intercalado y adecuadamente modulado. Por eso es conveniente, y, hasta cierto punto, necesario, delimitarlo con dos comas, y no sólo con una al final como reconoce el propio Ferrín. La coma después de la elisión es la que marca la diferencia de entonación de esta verso de la del verso 11, donde se da la misma elisión, pero sin coma.

$\mathrm{El}$ anacolurto, si es que es un anacoluto, Omeu amig',..., mentirlh'ey, en lugar de : A meu..., junto con el dativo, hoy inusitado, a que, en el sentido dé "a quen", dificulta para nosotros el entendimiento del dístico, y por lo tanto también su recitado. La contracción de $a 0=0$, que propiciaría la formación anacoluta, se explica, como apunta muy bien Ferrín. por el fenómeno intencional de la lengua hablada y afectiva de poner adelantadamente en primer término como si fuera sujeto lo que lógicamente es dativo objeto.

Pienso que más que expresión anacoluta se trata de una absorción o asimilación de la $a$ por la $o$, con lo cual ésta adquiere una pronunciación abierta que la distingue claramente de la pronunciación cerrado de la $o$ no-

"CUADERNOS DE ESTUDIOS GALLEGOS", Tomo XXXIX, Fascículo 104, Santiago 1991. 
minativa. En el verso que puntualmente comentamos, la asimilación de la preposición por el artículo viene favorecida también por la segunda mención: $a$ que..., que suple sobreentendidamente la primera, aminorando así el nominativo anacoluto, $\mathrm{y}$, por consiguiente, haciendo más plausible su justificación estilística. Ni M. Ferrín ni A. de Azevedo han tenido en cuenta la $h$ no etimológica unánime de los dos códices; y sin embargo creo que responde a razones métricas. La $h$ sirve para hacer más patente el carácter endecasílabo de ambos versos. A. De Azevedo, llevado de su esquematismo lógico pone coma después de fonte, interrumpiendo en demasía la continuidad recitativa del verso encabalgado. La $e$ de fonte suena clara, y la frase hu os cervos van bever exige una inflexión un poco más baja, pero sin romper la continuidad melódica de los dos versos. El dístico con los versos encabalgados forma una totalidad lírica indiscutible, marcada sin embargo con dos semipausas, la final del verso, con inflexión más alta hasta fonte, y la segunda, a partir de aquí con inflexión declinante hasta su terminación:

Talheilh'eu preyto de o hir veer' ena fonte'hu os cervos van bever.

Los versos del cuerpo de la cantiga son endecasílabos agudos. M. Ferrín considera sin embargo el 8 como decasílabo. A mi me resulta un poco extraño esta excepción. En el vero 7, el dativo proclítico $l h i$ suena naturalmente con plenitud aguda. Pues bien, en el verso siguiente, el mismo dativo en posición enclítica, por tratarse de frase contrapuesta, ha de pronunciarse con el mismo énfasis, marcadndo tambiénm la $i$. Leído así el verso, que es como creo que hay que leerlo, resulta también endecasílabo. No me puedo imaginar que el poeta no haya sido consciente del isosilabismo de la composición.

El futuro perfecto obligativo regido por la preposición $a$, con que se cierra el último dístico de la cantiga: a mentirlh'averey, parece destinado a reforzar con más intensidad lo ya expresado más débilmente en el segundo verso del primer dístico. A. de Azevedo lo interpreta como "regencia arcaica" sin ejemplarizar tal regencia.

Como ya queda indicado, la incipiente manifestación lírica que gradualmente irá en aumento en la cantiga siguiente, corre a cargo del segundo verso del dístico segundo, con la mención simple, pero ya evocativa, de la fuente y los ciervos, los dos elementos esenciales, paisajístico y animístico, que aparecerán ya reiteradamente condensados en el estribillo de la segunda cantiga. En la cantiga primera predomina la tensión dramática entre la madre y la hija, corroborada por la insistencia machacona del estribillo, que marca, frente a las admoniciones sobreentendidas de la madre, el empeño indisuasible de la hija de no faltar a la cita convenida. 
Por esta firme actitud de la amante creo que el estribillo debe estar deslindado del cuerpo de la cantiga mediante punto, y no por punto y coma como hace M. Ferrín, que indica una separación demasiado débil. En cambio juzgo inadecuada la separación entre comas de la condicional intercalada si non for, como hace A. de Azevedo. Esta puntuación, practicada anteriormente por J.J. Nunes, en Cantigas d'amigo dos trovadores galego-portugueses, fue tachada ya de excesivamente lógica por M. Ferrín, pues se trata de un "único grupo fónico... que está mais perto da realidade fonética actual e, sen dúbida, da medieval. Esa geminación es, pues, además de innecesaria, contraproducente, porque resta rotundidad al estribillo.

\section{Cantiga II}

Sigue hablando la amante, ahora en verdadero monólogo. Como se desprende del texto de la cantiga, y, como era de esperar, la hija desatiende los consejos de la madre, y se presenta a la cita. Ahora quien se ensaña es ella, "fremosa", herida en su amor propio y en su orgullo femenino, y con sobrada razón: por el atrevimiento del amigo de pedirle una cita en la fuente; por el desaire de que la ha hecho objeto no acudiendo, hecho no previsible siendo ella tan hermosa; y, finalmente, se sobreentiende, por cierta mala conciencia de haber desobedecido a la madre. El despecho de la amante sube de punto en la última estrofa, pues el desplante sufrido, además de una informalidad, es como una mofa, como si el amigo se burlara de ella y la tuviera por tonta: "Affeito me ten ja por sendía". He aquí, pues, la cantiga de despecho:

Por muy fremosa, que sanhuda estou

a meu amigo, que me demandou

que o foss'eu veer

a la font'u os cervos van bever.

Non faç'eu torto de mi lhassanhar

por s'atrever el de me demandar

que o foss'eu veer

a la font'u os cervos van bever.

Affeyto me ten ja por sendia,

que el non ven, mas envya

que o foss'eu veer

a la font'u os cervos van bever.

En esta cantiga, así tensamente monologada por la amante, la expresión "non ven", en presente expectativo, resalta la impaciente y acuciante ansiedad de la espera, mientras la adversativa "mas envya", en presente 
histórico, torna más ocular y palpable el enojo de la amante hacia el amigo por la frescura de haberle solicitado la cita y no aparecer. El despecho se mitiga y compensa sin embargo ante la visión deleitable de la naturaleza, donde toda agitación del alma se serena y aplaca. El efluvio lírico incipiente ya en la primera cantiga mediante la simple mención de la fuente y de los ciervos que a ella van beber, se intensifica ahora a través del endecasílabo que cierra el estribillo de cada una de las tres estrofas en un conjunto unitario. El receptor de la cantiga siente que la sandez no es aplicable a la amante amiga, sino más bien al amado amigo por no haber acudido a una cita de amor en lugar tan apacible y deleitoso. El paso de la rabieta de la muchacha, tan vivamente expresada por los endecasílabos iniciales de los dos primeros dísticos y por el decasílabo del tercero: "Por muy fremosa,..." "Non faç'eu torto..." "Affeyto me ten...", al remansamiento lírico del dístico del estribillo formado por la adecuada combinación de heptasílabo y endecasílabo, se verifica en suave transición mediante el encabalgamiento del segundo endecasílabo de las dos primeras estrofas y del octosílabo de la tercera, que desembocan en el heptasílabo del estribillo, el cual a su vez, con idéntico encabalgamiento, y por consiguiente sin la menor detención de la fluencia anímica, se une al endecasílabo evocador del idílico paisaje de la fuente que los ciervos frecuentan impulsados por la sed. Con ello se ha logrado una integración en perfecto equilibrio entre la tensión dramática de los dísticos del cuerpo de la cantiga y el clima lírico que impregna y circunda el dístico del estribillo. El mayor encanto de esta cantiga consiste precisamente en ese paso delicado de los tres dísticos de la cantiga al dístico del estribillo. Este tránsito se ve muy claramente en los cuatro versos de la segunda estrofa, la más fluida, en la que cualquier coma resultaría superflua por no decir contraproducente.

Azevedo sin embargo pone coma después de assanhar y después de font'. Pero esta puntuación excesivamente lógica interrumpe en demasía la corriente lírica que mana de la cantiga. M. Ferrín ha señalado ya a este respecto el "perfeito acoplamento entre o corpo da composición e mailo refrán". Yo hago diferencia entre el verso de la primera cantiga ena fonte hu os cervos van bever y éste aquí a la font'u os cervos van bever. En el ms.C.V. la $e$ de fonte fue elidida primero, pero luego se suprimió la elisión escribiendo la $e$, y ésta es la lectura correcta del ms.B.N.: Ena fonte $h u . .$. de la primera cantiga, la $h$ no etimológica tiene una doble función, pues admás de suprimir la sinalefa sirve para demarcar apositivamente la frase inmediata: hu os cervos van bever. Ena fonte se pronuncia con energía, cosa que no ocurre en hu os cervos van bever, que aparte de su papel aclarativo, lo esencial es ya su matiz líricamente evocador. Y este matiz eminente y exclusivamente lírico es el que transciende de: a la font' $u$ os

"CUADERNOS DE ESTUdIOS GALLEGOS", Tomo XXXIX, Fascículo 104, Santiago 1991. 
cervos van bever. Y por consiguiente ... a la font' no se puede pronunciar en este nuevo contexto con el enérgico subrayado del contexto anterior, sino que hay que hacerlo morosamente y sin detención. No hemos de omitir otro factor diferencial esencialísimo que viene en apoyo de lo que estamos diciendo sobre este verso, y es su posición en la cantiga. En la primera mención, como elemento aseverativo-descriptivo dentro del cuerpo de la cantiga tiene un cometido predominantemente activo; en la segunda cantiga, en cambio, al integrarse como parte esencial del estribillo, asume una misión puramente receptiva, evocadora. Una consideración acendrada de lo lírico no puede pasar por alto estas diferencias. No se trata, pues, de sutilezas, sino de realidades bien perceptibles en un texto lírico matizadamente interpretado. La coma que pone Azevedo después de font' es en este contexto totalmente inaceptable.

La expresión interjectiva "Por muy fremosa", con la que, a manera de juramento, la amante pone, como justificación de su saña, su hermosura, pide una coma. Azevedo no la pone, aduciendo que por ser el que comparativo no hay necesidad de tal coma. Yo no veo aquí ningún comparativo, sino la expresión rotundamente enérgica, más bien superlativa del juramento. Este juramento es muy original, y a la vez muy femenino, aunque nacido como forma paralela del juramento "par Dios", "vive Dios", propio del talante masculino.

Yo respeto la lectura sendia, que es la que traen los dos códices. Se conocen las dos formas "sendia" y "sandia". Carolina Michaelis de VAsconcelos la hizo derivar "sine Deo". Méndez Ferrín se inclina por la etimología propuesta por Diez: sancte Deus", un bendito o un alma de Dios, apoyándose en Corominas, que "lle apón a Dona Carolina a dificultade de que tal étimo non é axeitado a visión do mundo medieval, pois non se concibiría que ninguén, por moi fato ou parvo que vose, resultara acreedor da calificación de sen Deus nunha sociedade tan alleada relixiosamente". Aunque la etimología dada por doña Carolina no está lingùísticamente muy justificada, la explicación cultural de Corominas lo está todavía menos, ya que "sine Deo" no podría significar algo a'si como ateo, incrédulo o infiel, sino el abandonado de la mano de Dios, es decir,del que ha perdido el juicio. En la Edad Media, la locura era considerada como una enfermedad diabólica, y el padecerla equivalía a estar bajo la posesión del demonio; el paciente era, pues, un poseso. Perder la razón era tanto como "estar sem Deus" sin su protección, a merced del maligno. Y esta interpretación, que está de acuerdo con el sentimiento religioso de la Edad Media, lejos de desvirtuar la derivación de la señora de Vasconcelos, vendría a poyarla. La explicación de Diez no la veo apoyada en otros pasajes, y tampoco lo está en éste, pues es evidente que el término en el pasaje de Pero Meogo significa "loca" o persona que ha perdido su sano juicio, aun 
cuando es posible que "sandia" lleve implícita una segunda connotación². La traducción que da Azevedo del verso "Afeyto me ten já por sandia" =Já me tem por completamente louca de amor" es exacta. Pero no veo la razón de sustituir sendia por sandia, si ambas lecturas están documentadas. En este caso hay que atenerse al texto manuscrito, y, y todavía más, si los dos concuerdan. Por boca de la propia amante, el autor omnisciente quiere revelarnos ya aquí que la amiga está en efecto perdidamente enamorada del amigo.

\section{Cantiga III}

Entre la segunda y la tercera cantiga parece que hay un espacio episódico-narrativo, sin duda consciente o intuitivamente omitido en beneficio de la condensación lírica. Quizá amigo y amiga apalabraron una nueva cita, cita a la que esta vez no acudiría la amante, no tanto para cobrarse el desplante recibido, sin más bien para despertar celos en el amado, y con-

${ }^{2}$ El prehistoriador y lingüista Luis Monteagudo me sugiere otra derivación: "sen/ sandia" vendría de la hipotética forma "semitiva". Adiect. "a semita ad semitam pertinens. "semitarii moechi (apud Catullum, 57, 16) sunt meretrices triobolares consectantur, in quadriuiis et angiportis et semitis prostantes". Plaut. Curc. 1.1.33: "dum ne per fundum septum facias semitam, dum tete abstineas nupta, vidua, virgine iuventute et pueris liberis, ama quodlubet". "Semita (senda) itineris dimidium est, a semitu dicta. Semita autem hominum est, calles (trocha) ferarum et pecudum" (Etym. XV, 16, 9). Significa, pues, no sólo la vía .apartada y secreta, sino también, en sentido traslaticio, la vida que se desvía del camino recto: "An secretum iter, et fallentis semita vitae". En las Cantigas de Santa María, de Alfonso $\mathrm{X}$ el Sabio, aparece muchas veces la expresión en la forma masculina y femenina. Mettmann IV (glosario) las registra todas. He aquí tan sólo tres ejemplos con palabras afines: "ben louco fust'e sandeu", 245, 111; "loucam maa e sandia", 125, 106; "Uua moller aleimãa, tafur e sandia", 136,23. Y Gonzalo de Berceo, Milagros, vv. 646-647, ed. de A.G. Solalinde, Cla.Cast., p. 150, dice: "Entiendo que me tienes por loco e sendio, / que non traio conseio, e ando en radio". Berceo parece entender "loco" por hombre sin juicio, incapaz de consejo; y "sendio", por extraviado, errado o perdido. En ambos autores, "sandia" (con o sin acento sobre la $i$ ) y "sendio", llevan vinculadas las asociaciones de "logo/loca", "mala" y "tahur". Ahora bien, es propio de la poesía narrativa (Berceo, Alfonso X) amplificar o desarrollar un concepto con otros más o menos afines. Por el contrario, el poeta lírico (Pero Meogo) tiende a condensar en un solo término otros limítrofes. Es por lo tanto muy verosímil que la palabra en nuestro pasaje encierre una segunda connotación, a saber, además de "loca, "perdida". Sería, pues, una designación eufémica puesta en boca femenina, aquí la propia interesada, en el sentido de perdida o mujer de mala vida. La derivación que acabamos de exponer partiendo de "semita" (=senda), según la sugerencia de L. Monteagudo, sería una forma paralela del castellano sendero". En port. "sendeiro" tiene todavía la significación de algo despreciable. En cast. "asenderar" y "asenderado" nos recuerdan también la signi- 
seguir de paso prueba de su amor, aún no, o todavía no plenamente, correspondido. La omisión de este real o hipotético encuentro está sin embargo formalmente justificada: en el género de las canciones de amigo, el verdadero protagonista no es el amado, sino la amante, y ésta nos pone ante el hecho del alejamiento por parte del amigo, sin declararnos la motivación del mismo. Si la cantiga anterior, como queda apuntado, es de despecho, ésta es de distanciamiento. Sea cual fuere, pues, la causa de este distanciamiento, necesario en todo caso para avivar el amor por la pena de la ausencia, lo esencialmente lírico aquí son esos rápidos, alados versos, que bien pudieran haber servido a San Juan de la Cruz para transcender la esfera del amor humano a la del amor divino:

- Tal vay o meu amigo con amor que lh'eu dey, como cervo ferido de monteyro d'el rey.

Tal vay o meu amigo, madre, con meu amor, come cervo ferido de monteyro mayor.

El efecto lírico de los dos primeros dísticos se intensifica con la plástica imagen venatoria de los dos respectivos del estribillo. La amante, concierto aire de triunfo, declara a la madre, su natural y más cercana confidente, que el amigo va herido, tocado al fin por el amor que ella le ha infundido.

Pero este sentimiento de seguridad vacila de pronto ante la duda que la asalta: la huida del amado puede significar su pérdida, su posible muerte en el mar:

E se el vay ferido

hirá morrer al mar.

Sí fará meu amigo, se eu d'el non penssar.

"Irá" y "fará" son futuros de probabilidad que se pueden convertir en realidad si la amante abandona al amado, ausentándole de su pensamiento: se eu d'el non penssar. La coma que pone Azevedo después de la conjunción $e$ es antilírica. M. Ferín pone tan sólo una coma después de "mar". Azevedo pone punto y coma. Yo soy más radical y pongo punto. Nótese que la amante está hablando a la madre que la escucha escéptica. La hija lo nota, y acentúa su temor haciendo del futuro un hecho cierto, como si dijera: "Sí, lo hará, madre, si yo no pienso en él". El mar aquí, 
en contraposición al agua dulce que mana de la fuente, significa el elemento amargo del desengaño. El amigo quizá se embarque desafiando la muerte, o bien para guerrear en la Frontera contra el moro o para dirigirse a Ultramar como cruzado. No hay precedente, ni tampoco es necesario, de que el ciervo vaya a morir al mar. El bestiario medieval, que todavía traeremos a cuento, dice tan sólo que los ciervos cuando pasan grandes ríos lo hacen con facilidad llevando sucesivamente apoyadas las cabezas de los unos sobre las ancas de los otros. Pero un precedente del amigo abandonado a la salada hostilidad del mar por pena de amor, aunque no señalado por M. Ferrín ni por Azevedo, sí que existe, y exactamente en el mismo sentido del pasaje que estamos comentando. En una canción de amigo francesa conservada en un manuscrito único de avanzado el siglo XIII bajo el título de Chansonnier du Roi, dice la amante amiga: Biauz douz amis, con porroiz andurer / la grant painne por moi en mer salee...? (=Mi bello amigo amado, ¿cómo podrás soportar la gran pena de mi ausencia sobre el mar salado? $)^{3}$. La amante Eternizada por Pero Meogo siente en su propia carne la supuesta herida inflingida al amado, y ahora está temerosa de perderse perdiéndolo.

Quizá el amado no se ausentó realmente, quizá no fue más que un ardid, una ausencia fingida. Pero Meogo, con esta técnica elusiva, tan certera y repetidamente señalada por M. Ferrín. se limita a sugerir una ausencia del amigo, pero sin confirmarla. Es la madre la que nos inclina a la sospecha de una ausencia simulada. La madre, en su función de coro, preocupada por la suerte de la protagonista de amor, aunque en el fondo se sienta impotente para torcer el curso natural de las cosas, previene a la hija, trayendo a la memoria su propia experiencia. También ella amó a un amigo que se fingió apenado, tal vez recurriendo al mismo ardid para alcanzar su objeto:

- E guardádevos, filha,

ca ja m'eu atal ví

que sse fez coitado

por guaanhar de min.

\footnotetext{
${ }^{3}$ Peter Dronke, The Medieval Lyric, $2^{\mathrm{a}}$ ed. London 1978, p. 107 y ss. El autor, que cree que esta canción no pudo ser escrita sino por una mujer, acompaña el texto francés con una trad. inglesa, seguido de un comentario muy certero, y lo apuntaba con una cita de Rilke. Vid. el pasaje en la n. 2 de la cantiga siguiente. El famoso Manuscript du Roi, de la Bibl. Nat. de Paris 844, aunque muy deteriorado, contiene todavía elegantes iniciales con retratos y blasones de "trouveres et troubadours". Vid. Chansonnier As. en Lexikon des Mittelalteos, p. 1709. Artemis Verlag München unid Zürich 1983.
}

"CUADERNOS DE ESTUDIOS GALLEGOS", Tomo XXXIX, Fascículo 104, Santiago 1991. 
E guardádevos, filha, ca ja m'eu ví atal que se fez coitado por de min guaanhar.

En estas dos estrofas pronunciadas por la madre no hay más comas que las que separan el vocativo "filha". Es totalmente innecesaria y además antilírica la coma que pone Azevedo después de "coitado". M. Ferrín reconstruye la lectura "fez" de los manuscritos por "fezo" para completar el heptasílabo. Pero es probable que tal reconstrucción sea innecesaria, pues seguramente "coitado" se pronunció con diéresis, como nos sugiere la pronunciación de "gua-anhar", procedimiento equivalente a hacer este verso también heptasílabo.

Me parece que se alude aquí a hija de mujer soltera y de varón noble o tal vez clérigo, circunstancia que excluiría un enlace legal. Esta consideración vendría a confirmar también por este lado e carácter popular o semipopular de estas canciones ambientadas en un medio rural y feudal, y del que todavía se pueden detectar algunas supervivencias en la Galicia de nuestros días. Ahora bien, no creo que este medio natural que la canción nos sugiere esté cercano al mar; al contrario, se adivina más bien lejano, típica alusión a un elemento hostil y peligroso. En todo caso no es un mar familiar como el de Martín Codax o de Payo Gómez Chariño. En Pero Meogo, como en Mendiño, el mar es para la amante algo hostil que la separa del amado o se lo arrebata. El mar, dice a este propósito Dronke, es tardanza, espera sin esperanza, separación.

\section{Cantiga IV}

El distanciamiento real o simulado del amigo provoca un sentimiento de pesadumbre en la amante, la cual, desolada y perpleja por la ausencia del amado, se dirige a las ciervas solicitando su consejo ante el miedo angustioso de una tardanza incierta y prolongada:

Ay, cervas do monte, vinvos preguntar,

foyss'o meu amigu, e se alá tardar, qué farey, velidas!

Ay, cervas do monte, vínvolo dizer,

foyss'o meu amigu, e querría saber qué faría, velidas!

Es esta la cantiga de la queja, del lamento, que cobra así dimensión elegíaca. La amante invoca a las criaturas en estado de naturaleza como los únicos seres capaces de hacerse eco de su dolor. Este dolor de ausen- 
cia adquiere su rápida culminación en la segunda estrofa. No se trata tanto de una pregunta como de una confesión: vínvolo dizer. Es, pues, preferible el empleo del signo interjectivo, como hace Azevedo, al interrogativo utilizado por Ferrín. Por esta misma razón es más acertada la coma al final del primer verso de cada una de las dos estrofas que los dos puntos empleados por Ferrín. En los dos códices se lee en el último verso, como variante del estribillo, faría, y no veo por qué ha de uniformarse el estribillo con un farey, como hace Ferrín. Al contrario, la variación dispara la perplejidad en el doble aspecto temporal del futuro apodíctico y del futuro hipotético, introduciendo una ambigüedad lírica justificable: ¿qué haría, qué podría hacer la amante durante la ausencia del amado? O bien: ¿qué podría hacer éste sin la presencia, sin la compañía de la amante? Azevedo se decide por la segunda interpretación, coincidiendo así con la amante francesa del Chansonnier du Roi. Dejemos nosotros flotando, también perplejos, ambas posibilidades, porque a la postre, la interrogación invocativa de la amiga no es otra cosa que la manifestación de su estado subjetivo, susceptible de integrar unitivamente en su yo el del amigo. Si la amante sufre de amor de ausencia, ¿cómo podría dejar de sufrir el amado alejado de ella? Llegado a este punto he de declarar mi disentimiento de los que, como M. Ferrín y Azevedo, especialmente el segundo, por respeto a la lectura de los dos manuscritos, consideran inaceptable la sustitución de cervos por cervas. Por principio general de historiador, es justo atenerse al texto de los manuscritos. Pero en este caso no juzgo indispensable observar con tanto rigor la literalidad. Una copia del s. XVI hecha por escribas que probablemente no estaban familiarizados con el gallego, y que tal vez tampoco serían capaces de transcribir con absoluta fidelidad un texto del XIV, no merece esa respetuosa infalibilidad que le otorga Azevedo. Pero la razón última de mi disconformidad no está determinada tampoco por la mera concordancia gramatical, aun cuando me parezca muy correcta, de cervas con velidas, las eternas amantes típica y tópciamente categorizadas en los Cancioneros, sino por una necesidad inmanente. La amante no podría invocar a los ciervos (los amigos), porque éstos no la escucharían. Su destino es pasar de largo: "Como ciervo huíste / habiéndome herido, / salí tras ti corriendo y eras ido", dice San Juan de la Cruz, intérprete de fiar. Aparte de ese fondo lírico, matriarcalmente receptivo a que habré de referirme todavía, creo oportuno aducir aquí las palabras de Peter Dronke a este respecto, y a las que me adhiero con plena aprobación: "En muchos lieder gallegos, las ciervas, como encarnación de todo lo indómito y ardiente en su propia naturaleza, son simbólicamente las confidentes de la muchacha enamorada" y añade en nota: "Estas asociaciones me parecen estar más próximas a los lieder del siglo XIII que a la tradición popular de los mimos erótico-paganos y 
paganos y de sus ritos con todo el simbolismo del ciervo que en ellos se oculta, aun cuando no haya que descartar este posible trasfondo aducido, probablemente con razón, para los lieder gallegos, en los que aparece dicho símbolo"4. Rilke, de conocer estas canciones, hubiera temblado de emoción. Y el propio Dronke equipara la muchacha enamorada de las cantigas de amigo con las heroínas de amor ensalzadas por Rilke, el poeta de las amantes abandonadas: "Entonan su queja por el amado; mas la naturaleza toda entera suena al unísono en su corazón: es la queja por un amor eterno. Se precipitan tras el amado perdido, lo adelantan ya a los primeros pasos, y delante de sí no tienen sino a Dios"s.

\section{Cantiga V}

Al fin parece que hay noticias del amigo; quizá no estaba lejos. El narrador omniscente nos insinúa su aparición o su vuelta mediante los preparativos de la amante para esperar y recibir al amado. La amiga se levanta y se encamina a la fuente a lavar sus cabellos.

He aquí la cantiga de expectación:

Levouss'a louçana,

levouss'a velida,

vay lavar cabelos

na fontana fria,

leda dos amores

dos amores leda

Levouss'a velida, levouss'a louçana, vay lavar cabelos na fria fontana, leda dos amores, dos amores leda.

\footnotetext{
${ }^{4}$ In many of the Galician songs the hinds (cervas) are symbolically the confidentes of the girl in love, embodyng all that is farouche and that is ardent in her own nature: "These associations seem to me more immediately relevant to the thirteenth century songs than the folkloristic survival of erotic pagan mimes and rites filled with stag-symbolism-thougt, as has been argued, these too may well he behind the Galicien deer-songs". (Peter Dronke, The Medieval Lyric, second edition 1978, p. 104).

5 "Sie klagen um einen; aber die ganze Natur stimmt in sie ein: es ist die Klage um einen Ewigen. Sie stürzen sich dem Verlorenem nach, aber schon mit den ersten Schritten überholen sie ihn, und vor ihnen ist nur noch Gott”. Die Aufzeichnungen des Malte Laurids Brigge. Sämtliche Werke, vol. VI, p. 924.
}

"CUADERNOS DE ESTUDIOS GALLEGOS", Tomo XXXIX, Fascículo 104, Santiago 1991. 


\begin{abstract}
Vay lavar cabelos
na fontana fria, passou seu amigo que thi ben queria, leda dos amores, dos amores leda.

Vay lavar cabelos na fria fontana, passa seu amigo que a muit'amava, leda dos amores, dos amores leda.

Passa seu amigo que thi ben queria, o cervo do monte a auga volvia, leda dos amores dos amores leda.

Passa seu amigo que a muit'amava, o cervo do monte volvia a augua, leda dos amores, dos amores leda.
\end{abstract}

El poeta se hace eco del estado de felicidad de la amiga ante la expectante llegada del amigo; y nos la comunica también a nosotros participativamente mediante ese bellísimo estribillo, que impregna ya de lírico sentimiento la primera estrofa, y, en sucesión reiterada, todas las demás. Ante este sentimiento así tan alacre y alborozadamente expresado, prefiero la levedad de las comas empleadas por Ferrín a los dos puntos y punto de Azevedo. El sentido es diáfano, y una puntuación tan marcada resta agilidad y desenvoltura de la acción. El estribillo, íntimamente unido a las estrofas a manera de aposición, subraya y culmina el estado de rebosante alegría de la amante amiga, y en consecuencia no es lícito separarlo mediante el punto, como hace Azevedo. El punto y los dos puntos son recursos propios de la parataxis dramática, pero no de la parataxis lírica, que es la que aquí cuenta. Quizá debiéramos mantener la forma dus amores, que es la que aparece en el manuscrito, al menos en la primera men-

"CUADERNOS DE ESTUDIOS GALLEGOS", Tomo XXXIX, Fascículo 104, Santiago 1991. 
ción, y que tal vez fuese la primitiva del original. Es muy posible que con esta lectura el estribillo reprodujera más acariciadoramente toda la gama vocálica, resultando así también más dulce para el oído galaicoportugués de entonces. En las dos primeras estrofas, el acto intencional y su ejecución inmediata, por no decir simultánea, se logra gracias a la afortunada conjunción del pretérito puntual en su significación perfectiva, y a la vez evocativa, con el presente dinámico "vay", expresivo de movimiento externo. El pretérito puntual evocativo al comienzo de las dos primeras estrofas, acentuando su efecto actual y subjetivo mediante la iteración, va a quedar suplantado por el presente "ad oculos" "pasa", que ahora aparece en primer término en las estrofas tercera y cuarta, acentuando de este modo reiterativo su valor deíctico. Los recursos paralelísticos, predominantes en estas composiciones, combinados con la parataxis o yustaposición lírica de las estrofas que estamos considerando, y cuyo efecto resulta acrecentado por el hermoso "chiasmus" del estribillo, prolongan el encanto inefable de la idílica escena de la amiga en la fuente. Este motivo paijístico, realzado por la aliteración evocadora de la "fontana fria" "fria fontana" se redondea al ser recogido en las dos estrofas siguientes, tercera y cuarta, en las que se presenta al amigo como de paso, primero en la forma "passou", paralela a la de "levousse", pero no repetida acogedoramente como en las dos secuencias bimembres de los versos iniciales de las dos primeras estrofas destinadas a ensalzar la lozana belleza de la amante, sino tan sólo una vez: "passou seu amigo/que lhi ben queria".

El poeta se limita a decirnos que "pasó", así en perfecto absoluto, desligadamente, sin referencia vivencial, sin decirnos lo que pasó. Pero eso que pasó, en su dimensión o proyección masculina, es aquí algo transitorio, y por consiguiente, en el sentido receptivo de lo matriarcal y a la vez original, no es asunto de mucha monta. En las estrofas que siguen, como en el presente épico-lírico "vay", se pasa también aquí al presente "passa". Pero, como fácilmente se advierte, en este caso se trata más bien de un presente histórico, de un pasar transferido ya al recuerdo de la amante, evidenciado a través de la forma compensatoria imaginada del imperfecto "queria" y "amava", que pone de relieve el proceso durativo del sentimiento amoroso. La hypotaxis prosaica de relativo adquiere emoción lírica al ser transcendida a la esfera de la amante en virtud de esas agrupaciones bimenbres en alternante sinonimia: "passa seu amigo / que a muyt'amava" - "passa seu amigo / que lhi ben queria".

La cantiga V puesta sin duda por Pero Meogo en el centro de su cancionero, como pieza clave del mismo, concluye con dos estrofas que parecen querer entregarnos el secreto alegórico de la acción. En la cantiga III hemos visto al amigo "como cervo ferido". Ahora se concreta más. El amigo aparece identificado cn el cervo montaraz, que acude a la fuente de 
agua clara. Ya a mediados del siglo XII, Hildegard von Bingen, poeta mística e investigadora de la naturaleza, en la secuencia Columba aspexit, dedicada a S. Maximino de Tréveris, había escrito: "Ipse velox cervus / cucurrit ad fontem purissime aque fluentis..." Pero el ciervo de Pero Meogo, en contraposición a la actitud apacible de la doncella, llevado de su impetuosa e impaciente fogosidad, resuella y escarva con sus pezuñas el fondo y revuelve el agua: "O cervo do monte a augua volvia" - "o cervo do monte volvia a augua". Con estos dos versos se quiere sugerir evidentemente la acometividad sexual masculina. Pero no pasa de ser sino una discreta alusión, y si el poeta no nos declara más, sus razones tendrá, y no es necesario ni conveniente que nosotros desvelemos lo que él ha querido dejar delicadamente velado. Tal vez en atención a la natural inocencia de la doncella, que no es consciente todavía de las verdaderas intenciones del amigo, y se complace simplemente en el juego del "baile" iniciado por el macho como antesala o preludio del acto amoroso. Pero lo importante aquí no es el acto final, lo decisivo es la lírica y vivencial leticia que fluye sostenida y seguirá fluyendo ex abundantia cordis de la doncella en esta imperecedera cantiga. El poeta Pero Meogo, mediante ese evocador y plástico estribillo de dos palabras brotadas entrelazadamente al acorde del sentimiento, ha eternizado, como en el mito de Leda, la inmarcesible delectación del momento fugitivo.

\section{Cantiga VI}

En la cantiga anterior, el poeta nos hizo partícipes del júbilo de la doncella por el retorno y encuentro, aunque fugaz, de su galán. Ese sentimiento de felicidad colmada por la presencia del amado nos llega ahora directamente por boca de la propia amante que lo actualiza evocadoramente en el recuerdo. El poeta concede de nuevo la palabra a la protagonista de amor:

Enas verder ervas

vi andalas cervas, meu amigo.

Enos verdes prados

vi os cervos bravos, meu amigo.

E con sabor d'elhas lavey minhas garcetas meu amigo.

E con sabor d'elhos lavey meus cabelos, meu amigo. 


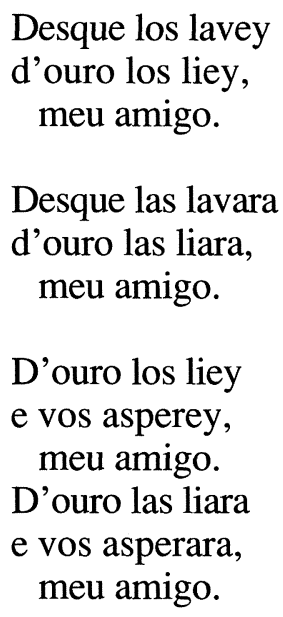

En la cantiga IV, la de la queja, la amante había invocado desolada a las ciervas del monte. Ahora, rebosante, pletórica de sentimiento amoroso, se complace en rememorarlo en agradecida comunión animística con las criaturas simbólicamente más cercanas, sin diferenciación de sexo, ciervas y ciervos. Pero con mención prioritaria de las primeras. Se representa así una idílica escena donde la agreste fogosidad de "os cervos bravos" aparece remansada gracias a la catártica receptividad femenina encarnada en las ciervas. El infinitivo "andar", con asimilación de la $r$, vale sólo para las ciervas, pues traduce de manera muy intuitiva y gráfica el movimiento interno de la muchacha enamorada, ahora externamente visualizado ante la imagen de sus compañeras las ciervas. Este movimiento circular, concentrado en sí mismo, responde a un sentimiento profundo y duradero emanado de una naturaleza muy diferente de la impulsiva que aguijonea a "os cervos bravos", pero por eso mismo más apasionada.

La amante recrea en visión retrospectiva unas vivencias, "os amores", que ahora, en estrecha asociación con el lugar ameno, adquieren una subyugante emoción lírica. Ella misma se siente en estrecha vinculación con las ciervas amigas. Repárese que el lugar por donde se mueven los ciervos, los "verdes prados", aparece visto en una perspectiva más distanciada. La proximidad de la fuente que verdea y perfuma la pradera nos sugiere una vez más el recuerdo de la estrofa ya aludida de Hildegard von Bingen, en la que, bajo la mística inspiración del Cantar de los Cantares, la escudriñadora de la naturaleza nos presenta al ciervo veloz acudiendo presuroso a la fuente clara que brota de empinada roca y expande suaves aromas: ad fontem purissime aque / fluentis simo lapide / qui dulcia aromata irrigavit. Es muy posible que también Pero Meogo no ande lejos de 
esta misma fuente de inspiración, aunque con una carga erótico-pagana que no encontramos en la sabia abadesa benedictina de Rupertsberg.

Enla estrofa tercera, y bajo la impresión de tan deleitable escena, la amante, enlazando con lo que ya sabemos por el poeta, que nos la presentó encaminándose a la "fontana fria" a lavar los cabellos en espera del amado, nos dice: "E con sabor d'ehlas / lavey mihas garcetas". Los cabellos sueltos o en mechones (garcetas) son símbolo, no sólo de virginidad, sino más concretamente, de mujer soltera (=soluta), es decir, no sujeta todavía al yugo marital. Cierto que ante la convención burguesa o cortesana de la época, la mujer "suelta" no gozaba de muy buena fama. Pero en un ambiente campesino como el gallego, de antiquísima tradición matriarcal, y por consiguiente aún muy unido a lo originario, esta condición de la mujer no sería un demérito grave, y sin duda tampoco lo era a los ojos de Pero Meogo, buen conocedor del medio rural. Hay, pues, que suponer que fue esta consideración lá que llevó al poeta a poner a la amante en relación con la cierva asustadiza y tímida, pero indómita, no domesticada, celosa de su vida natural en armonía con el mundo circundante, lo mismo en actitud de recato que de entrega abierta e incondicional. Sin embargo, a juzgar por las cuatro últimas estrofas y por ese vocativo exclamativo del estribillo, parece desprenderse que la amante se halla predispuesta a rendir su cara libertad a la voluntad del amigo. Lavó sus cabellos brillantes de oro y los lía o trenza sujetándolos tal vez con una cinta del mismo color; y así tan sencillamente compuesta esperó al amado. Pero por el contexto de la cantiga anterior sabemos que el amigo pasó de largo como ciervo fogoso e impulsivo, sin osar acercarse a la amiga que, cual cierva casta, le esperaba recogida en su feminidad, quizá sin dar muestras aún visibles de franca recepción.

En el vocativo exclamativo "meu amigo" me parece escuchar el velado y ligero reproche de que el amigo pasara sin acercarse a ella. Es muy difícil explicar satisfactoriamente el paso de los perfectos "lavey", "liey", "asperey", a los pluscuamperfectos "lavara", "liara" y, tal vez, "asperara". Méndez Ferrín dice que en este caso el pluscuamperfecto pierde su valor estricto: "desdibúxase e serve únicamente de sustitutivo poético, vagamente pasado, do perfeito". Yo me atrevo a ser un poco más explícito: pienso que la amante, atenta al tiempo íntimo de su corazón fluctuante, se siente movida a borrar los contornos precisos del tiempo formal, y así, mediante ese juego rítmico alterno, poder expresar la vacilación de sus sentimientos todavía indecisos. Con este procedimiento intenta hacer palpable la posible interferencia de lo real e irreal, el paso de uno al otro plano indistintamente. Esta consideración es la que me inclina a uniformar las terminaciones en -ara, escribiendo "asperara" y no "asperaua", como dicen ambos manuscritos, y que M. Ferrín respeta, pero probable- 
mente es un error de copia, error que también subsana Azevedo, aunque sin explicar el porqué. La forma "lavara" es sin duda pluscuamperfecta, pero no así "liara", que entraña sentido potencial, tanto en la antepenúltima estrofa como en la última. Si sustituimos el verso "e vos asperava" por "e vos asperara" se completa el esquema paralelístico contrapuesto: "D'ouro los liey / e vos asperey". "D'ouro las liara / e vos asperara". El cuadro de los cabellos atados es signo inequívoco de entrega inminente. El movimiento alternante de la cantiga, el locus amoenus y el añorante estribillo nos traen auras de himeneo. La amante, madura de amor, está a punto de sucumbir, pero la unión carnal aún no se ha consumado.

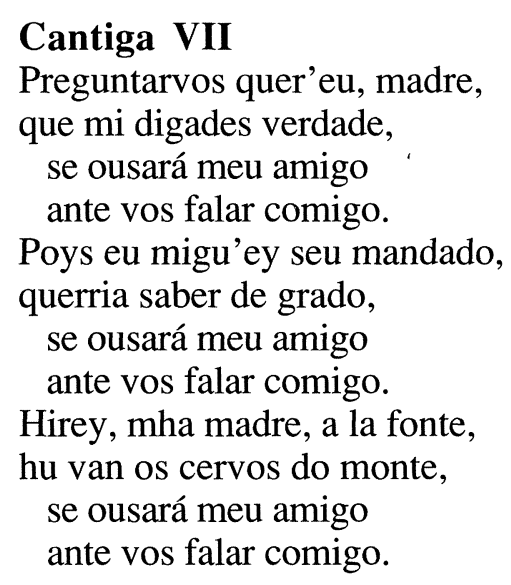

Como queda dicho, el acto sexual aún no se ha consumado, pero la entrega, el rendimiento de la amiga al amigo es inminente. torna el motivo del encuentro manifestado por la hija a la madre en la primera cantiga. Entonces era un escarceo, una aproximación; ahora es el movimiento profundo de la consumación. La situación conflictiva entre la madre y la hija se hace más tirante. La madre intuye la irreparable e irreversible situación de la hija, y pretende en vano, en un último intento, poner puertas al campo. Ya hemos visto que la madre es, a manera de coro, la voz objetivamente reflexiva y a la vez amonestadora del peligro que se cierne sobre la amante, y quiere detener o retardar el desenlace final, aunque en el fondo esté convencida, como lo estamos nosotros, su auditorio, de que la suerte de la hija está echada. Es una suerte querida y aceptada. La amante, como se nos ha hecho entrever en la cantiga anterior, presiente su destino y canta su derrota. Derrota? Victoria? Ambas cosas en una, lamento y júbilo. Es la voz elegíaca y jubilosa, irresistible y triunfante de la naturaleza. Con todo la hija intenta justificarse ante la madre, quizá también a la par, ante sí misma. En este caso la madre no pasaría de ser más que un 
pretexto de su yo desdoblado, su conciencia reflejada como en un espejo en la figura de la madre. Se supone, para dar más verismo a la escena, que la madre está presente, pero ello no deja de ser una suposición, porque la madre no habla. Formalmente considerada, la cantiga es un monólogo. Lo único que se dice es que la hija quiere preguntr a la madre si en verdad cree que el amigo podría hablar con ella en su presencia. Hay que suponer que este impedimento no lo sería tan sólo para el amado, sino también, y quizá aún en mayor medida, para la amante.

Se trata, pues, de una pregunta meramente formal, con miras a acentuar más la supuesta negativa implícita, pero supone, claro está, una admonición, que ahora se evidencia con más fuerza en presente. El peligro de ir a la fuente de los ciervos acaso pudiera evitarse si el amigo accediera a venir a parrafear con la amiga bajo la mirada vigilante de la madre. Pero tan saludable consejo es a todas luces inviable, y para rebatirlo, la hija termina por declarar tajantemente a la madre su decisión irrevocable. Es una decisión que ella formula en alta voz, pues ha recibido del amigo un recado, que es para la amante un mandato, un mandato que obra en su poder instándola de manera imperiosa a cumplirlo: "Hirey, mha madre, a la fonte / hu van os cervos do monte".

El estribillo aquí no tiene otra función que subrayar la resolución tomada frente a las prevenciones maternas. La interrogación indirecta entraña, pues, una respuesta irónica a una demanda utópica. El signo de interrogación usado por Ferrín desvirtúa un tanto la intención implícita.

Azevedo habla constantemente de un supuesto código familiar, comunitario o social y de su transgresión, y llega a afirmar que la madre "defende o código comunitario da sociedade medieval". Esta afirmación es muy arriesgada y al mismo tiempo muy vaga. Estamos todavía muy lejos de la fuerza del honor y de la honra dominante en una sociedad jerárquica constituida sobre la autoridad paterna. Aquí no aparece para nada la figura del padre, $y$ en el medio rural en que se desenvuelve la cantiga no imperan las convenciones rigurosamente establecidas y acatadas del mundo cortesano o burgués. La madre desea sin duda la seguridad material de la ahija, condición indispensable para la continuidad y supervivencia de la sucesión, y esta seguridad está mucho mejor garantizada a través de la institución cristiana del matrimonio. Pero entrevemos que este enlace santificado por la iglesia no parece posible debido a la diferencia social de las partes. El amigo es noble, cortesano o quizá clérigo; la amiga, campesina, hija tal vez de amores no legalizados. También existe la sospecha de que tras la figura del amigo se esconda la del poeta, o por lo menos se dejan traslucir rasgos autobiográficos o vivencias de su moecedad. Este es el medio en que habría que colocar la tarnsgresión de que habla Azevedo, un medio, como se ve, bastante laxo, y por lo tanto con espacio am- 
plio para la manifestación lírica y para la afirmación profunda del sentimiento compartido o en solitario. La muchacha es enteramente libre en la naturaleza libre, y las prevenciones de la madre no tienen poder coercitivo para la hija. La ventura o desventura amorosa radica en la naturaleza misma del eros como dimensión universal de la vida, y es independiente en último término de la infidelidad o cumplimiento de la promesa, si es que la hubo, por parte del amigo. En las cantigas no hay padre ni marido. El mundo de las cantigas es el reino de la madre y de la amante.

\section{Cantiga VIII}

Fostes, filha, eno baylar

e rompestes hi o brial.

Poys o namorado y ven, esta fonte seguidea ben, poys o namorado y ven.

Fostes, filha, eno loyr

e rompestes hi o vestir.

Poylo cervo hi ven,

esta fonte seguidea ben, poylo cervo hi ven.

E rompestes hi o brial que fezestes ao meu pesar.

Poylo cervo hi ven, esta fonte seguidea ben, poylo cervo hi ven.

E rompestes hi o vestir que fezestes a pesar de min.

Poylo cervo hi ven,' esta fonte seguidea ben, poylo cervo hi ven.

La madre, como coro o trasfondo mudo en las cantigas anteriores, entra ahora en escena. Esta cantiga es, como dice Ferrín, "a clave do sistema". La decisión de la hija expresada en la cantiga anterior mediante el enérgico futuro "Hirey, mha madre", aparece confirmada ahora por la madre: "fostes, filha". Las consecuencias están a la vista. La madre reprende a la hija por haber echado en saco roto sus consejos. Es una reprensión mezclada con un deje de reproche resignado, pero sin aspereza. Nos declara tan sólo que la caída de la hija ocurrió, dice, "ao meu pesar" 
- "a pesar de min". En el baile, en el juego con el ciervo amigo, la hija rompió el brial. Es el motivo del eufémico cántaro que va a la fuente y al fin se rompe. El baile como preludio del amor puede implicar una alusión a la antiquísima danza gallega de la muiñeira con sus lentos pasos iniciales paralelos, el enérgico enfrentamiento o desafío del punteado y, finalmente, la persecución en movimiento circular. La señalizada ruptura del brial "rompestes", subrayada a lo largo de todas las estrofas, pero mitigada ya al comienzo por la afectiva expresión "filha" - "filha", nos evidencia un hecho consumado: la virginidad perdida. Esta declaración hecha por boca de la madre nos revela sin duda algo más. Como mujer experimentada y quizá antaño en situación paralela a la de la hija hogaño, se hace solidaria con el destino de la hija, como fatal repetición del suyo.

En oposición a Azevedo, yo respetaría el punto que pone Ferrín al final de los dísticos. Las razones que da este autor me parecen convincentes, aunque Azevedo, llevado de su punto de vista formal o estrictamente literario no esta'dispuesto a aceptarlas y prefiere los dos puntos, que confirman más que separan. Pero no creo que sea éste el caso. Se trata más bien de delimitar dos planos diferentes, como se ve ya por el "cuerpo" físico del estribillo, mayor que el de la estrofa, procedimiento de suyo ya bastante chocante, si no respondiera a una finalidad conscientemente perseguida por el poeta. El primer plano, el de la estrofa, significa lo real, el hecho en sí, y a lo hecho pecho. En cambio el estribillo, como dice acertadamente Ferrín, "lévanos a un novo mundo, esta vez profundo, misterioso, conmovedor":

Poys o namorado hi ven,

esta fonte seguidea ben,

poys o namorado hi ven.

La madre desenmascara aquí el lenguaje eufémico de la hija, que llama ciervo al amigo amado. Pero luego, en las repeticiones siguientes del estribillo, en respetuosa y comprensiva actitud por la locura de amor de la hija, termina por solidarizarse animísticamente con ella, aceptando, entre bromas y veras, la identificación del ciervo con el amigo. Los dísticos siguen repitiendo machaconamente lo de la ruptura del brial, pero el estribillo, matizado de cariñosa ironía y líricas sugerencias, va ganando terreno sobre lo dado, y presentimos ya a las puertas el cambio de la madre, propicia a hacer causa común con la hija. Por el estribillo nos representamos al amigo dirigiéndose una vez más, ahora con muy buen sabor de boca, al lugar ameno de la cita, y a la amiga disponiéndose a ir a su encuentro, pues la madre, como en una bella e imaginada escena venatoria, alerta a la hija con irónico gracejo, y, para que no equivoque el camino, por lo demás bien sabido, de la fuente, le descubre, como si ya lo tuviera a la 
vista, la aparición y acercamiento del amigo ciervo. Naturalmente la madre no hace sino visualizarnos la representación del amigo en la fantasía de la hija.

\section{Cantiga IX}

- Digades, filha, mha filha velida, por que tardastes na fontana fria Os amores ey.

Digades, filha, mha filha loucana, por que tardastes na fria fontana.

Os amores ey.

- Tardey, mha madre, na fontana fria, cervos do monte a augua volvian.

Os amores ey.

Tardey, mha madre, na fria fontanà, cervos do monte volvian a augua.

Os amores ey.

- Mentir, mha filha, mentir por amigo, nunca vi cervo que volvess'o rio.

Os amores ey.

Mentir, mha filha, mentir por amado, nunca vi cervo que volvess'o alto.

Os amores ey.

La cantiga novena constituye la culminación del "opus" lírico de Pero Meogo. Como en una ópera, madre e hija aúnan sus voces en duo perfecto. M. Ferrín, aunque reconoce que no es imprescindible, en atención a una mayor vivacidad de la cantiga, pone signo de interrogación al segundo verso de los dos primeros dísticos. No sé si conviene entonar la frase con la vivacidad presumida. Al contrario, más bien parece acercarse intencionadamente al tono interjectivo. En realidad la pregunta no está tampoco dirigida a inquirir ni a obtener siquiera una explicación sobre lo que ha pasado o por qué ha pasado, sino más bien a suscitar en el oyente una actitud comprensiva y tolerante. La hija sabe muy bien que la madre está de su parte, y la respuesta parece concebida más bien de cara al auditorio, a la opinión pública, al que dirán. Y, claro está, quien pretende saber de-

"CUADERNOS DE ESTUDIOS GALLEGOS", Tomo XXXIX, Fascículo 104, Santiago 1991. 
masiado se queda en ayunas. La amante se vela discreta y exprsivamente tras la representación de los ciervos que enturbian el agua. Dejemos, pues, tranquilamente al tiempo, que borra todas las huellas, la tarea de serenar las aguas y devolverles su prístina transparencia. La construcción paratáctica de la filial respuesta comunica a estos dos dísticos centrales una perceptible agilidad dramática, a la par que los envuelve en una vaga, inefable atmosfera lírica. La contestación de la hija no convence, claro está, a la madre, que tiene los pies bien asentados sobre la tierra y no puede comulgar con ruedas de molino. Pero encubre y justifica a la hija, y termina respetando su estado de enajenación amorosa. El infinitivo "mentir", en su sentido abstractamente generalizador, soslaya una acusación directa lanzada a la cara de la hija. Tal es el sentido del texto, y por ello no es necesario enmendar la lectura del manuscrito, como hace Ferrín, por un supuesto "mentís", que tampoco paliaría la crudeza, más bien la agravaría con la iteración. Sin duda es una mentira, pero una mentira aminorada, perdonable, pues se trata de un subterfugio de la amante, un mentir por el amigo / por el amado, como nos declara la madre solicitando indirectamente la absolución de la hija. Con ese breve estribillo coreado por las dos, Pero Meogo proclama el triunfo de los "amores", es decir,del amor pagano en su sentido concreto, palpable, vivido. El poeta, por boca de la madre se despide de nosotros, no sin antes evocarnos el hermoso cuadro paisajístico de la fuente fría, que se hace rivus umbroso, corriente de aguas cristalinas, en cuyo fondo se refleja el cielo. "Alto" es una forma poética culta equivalente a "agua profunda". Esta transposición pervive aún en "alta mar" o "mar alta", paralela a la de "profundo cielo" El epithetum ornans, caracterizador por antonomasia, asume aquí esencial y diáfana función sustantivadora. 